\title{
INFERIORLY BASED VERTICAL RECTUS ABDOMINIS MYOCUTANEOUS (VRAM) FLAP FOR RECONSTRUCTION OF LARGE DEFECT AFTER WIDE EXCISION OF SOFT TISSUE SARCOMA IN PUBIC REGION
}

\author{
Santanu Sarkar ${ }^{1}$, Sukhamoy Saha², Manabendra Naskar ${ }^{3}$, Madhusudan Saha4, Prasenjeet Mondal ${ }^{5}$
}

\section{HOW TO CITE THIS ARTICLE:}

Santanu Sarkar, Sukhamoy Saha, Manabendra Naskar, Madhusudan Saha, Prasenjeet Mondal. "Inferiorly Based Vertical Rectus Abdominis Myocutaneous (VRAM) Flap for Reconstruction of Large Defect after Wide Excision of Soft Tissue Sarcoma in Pubic Region". Journal of Evolution of Medical and Dental Sciences 2014; Vol. 3, Issue 33, August 07; Page: 8912-8915, DOI: 10.14260/jemds/2014/3142

ABSTRACT: Malignant fibrous histiocytoma is the commonest form of adult soft tissue sarcomas, albeit very few cases have been reported arising in the pubic region. Large defect resulting after extirpation of such tumors pose a problem in their reconstruction. Wound closure with well vascularized tissue (flaps) is most suitable, which leads to early recuperation and avoids delay in instituting postoperative radiotherapy. We report a case in which a 42 years old lady presented with a large pubic region growth. We present this case firstly because sarcoma in pubic region is rare and secondly we use VRAM flap (Reversed TRAM flap) for reconstruction of large defect after wide local excision of the tumor, which is simple to execute with good functional outcome.

KEYWORDS: Pubic growth; Soft tissue sarcoma; Reconstruction; VRAM flap.

INTRODUCTION: Patients with large pubic or groin defects following tumor ablative surgery pose a particularly challenging reconstructive problem. Skin grafts in these situations are not suitable as they cannot give adequate protection to the underlying vessels and cannot withstand radiotherapy which is frequently needed. Taylor et al, have carefully detailed the vascular territory of the deep inferior epigastric artery.[1-2] Gottleib et al and many others also reported and strongly recommend VRAM flap for closure of such defects.[3]

CASE REPORT: A 42 years lady was admitted in our surgery ward with complaints of a large swelling over the pubic region for 2 years. Swelling initially was smaller in size and gradually progressive but for last 6 months there was rapid growth of the tumor, for which she seeks medical attention. She had no past history of trauma or surgical intervention to that site.

On local examination, a large, variegated, firm mass measuring 9 x $6 \mathrm{cms}$ was present [Fig 1(a)]. There was no regional lymphadenopathy. Her routine biochemical investigations were within normal limits. True cut biopsy revealed malignant fibrous histiocytoma. From CT scan of abdomen \& pelvis we decided it was an operable parietal tumor and not extending into abdominal or pelvic cavity. 
Figure 1: (a) lesion on pubic region (b) after excision of lesion \& VRAM flap prepared.

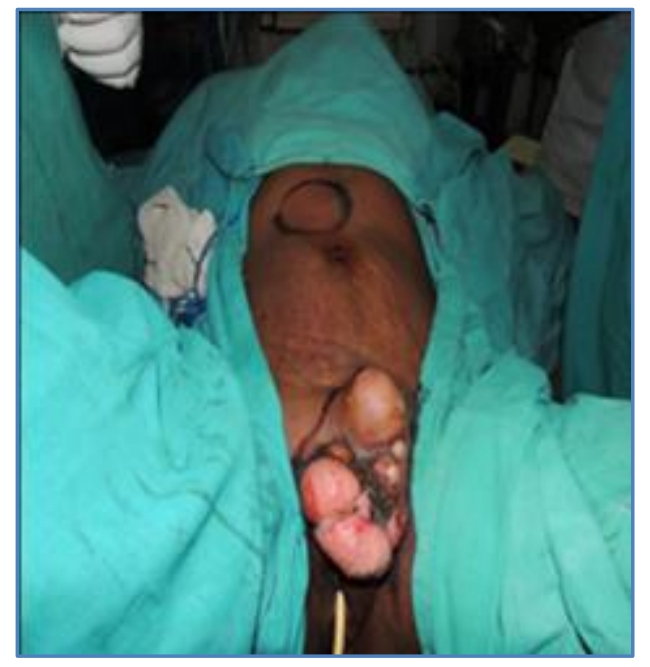

Fig. 1a

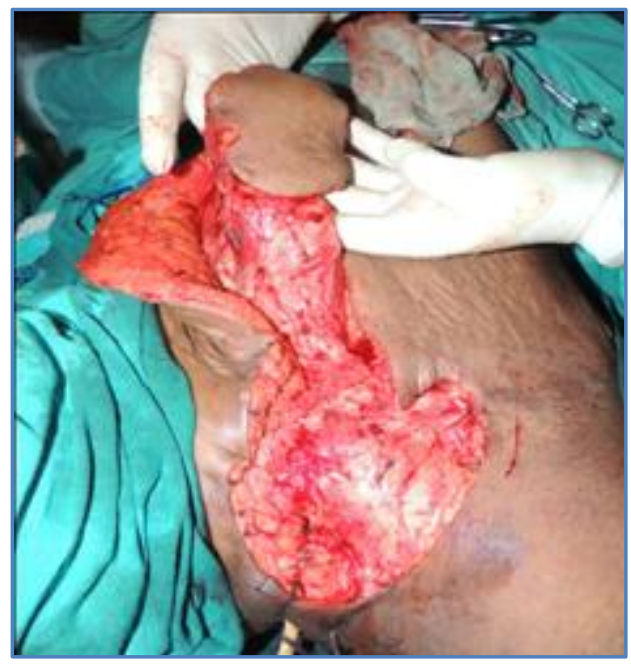

Fig. $1 b$

SURGICAL PROCEDURE: Entire tumor with $2 \mathrm{cms}$ macroscopic clear margin was excised along with underlying fatty tissue, fascia and upper part of vulva for proper oncological clearance as these structures were also involved.

Using separate instruments the skin island was designed appropriate to the defect [Fig.1b]. Incision had been made along the margins of proposed skin island down to the anterior rectus fascia (right side). At the superior border of skin island, anterior rectus fascia and rectus muscle was divided but posterior rectus fascia kept intact, then the incision followed lateral and medial borders of right anterior rectus fascia, keeping approximately $5 \mathrm{cms}$ width of rectus fascia intact with the flap, which ensures perforators coming off the anterior surface of the muscle through the rectus fascia are not interrupted.

Then the muscle was dissected off the posterior rectus fascia. VRAM flap was designed throughout the whole length of the muscle tapering towards the pivot point of the flap at the entry of the inferior epigastric pedicle.

The fasciomusculocutaneous flap then mobilized to the defect after incising the skin bridge to lay open the tunnel connecting recipient and donor sites. The donor site was closed primarily after reinforcement of the abdominal wall using an onlay prolene mesh, suction drains were used. Patient was mobilized within 1 week post operatively. Now patient is under follow up for last 12 months with no evidence of local or distal recurrence. 
Figure 2: (a) VRAM flap mobilized (b) 2wks postoperatively.

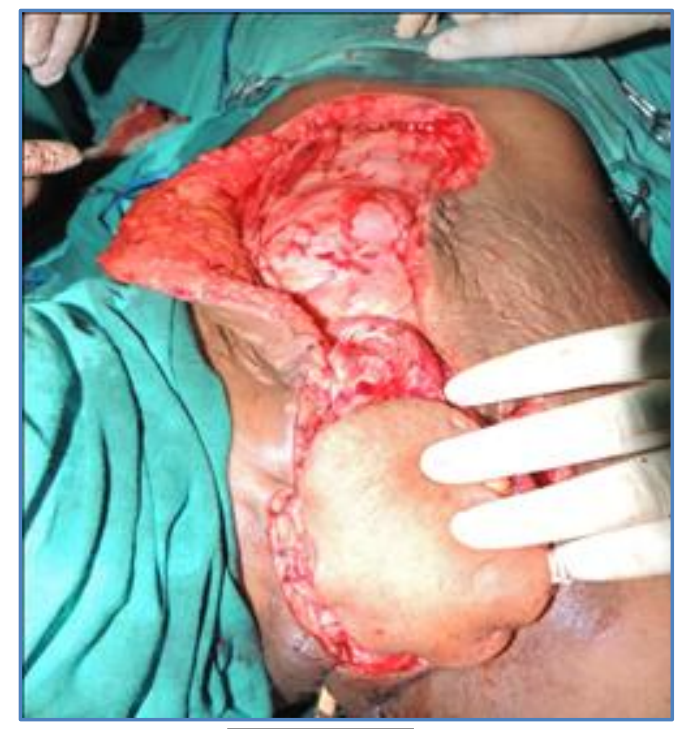

Fig. 2a

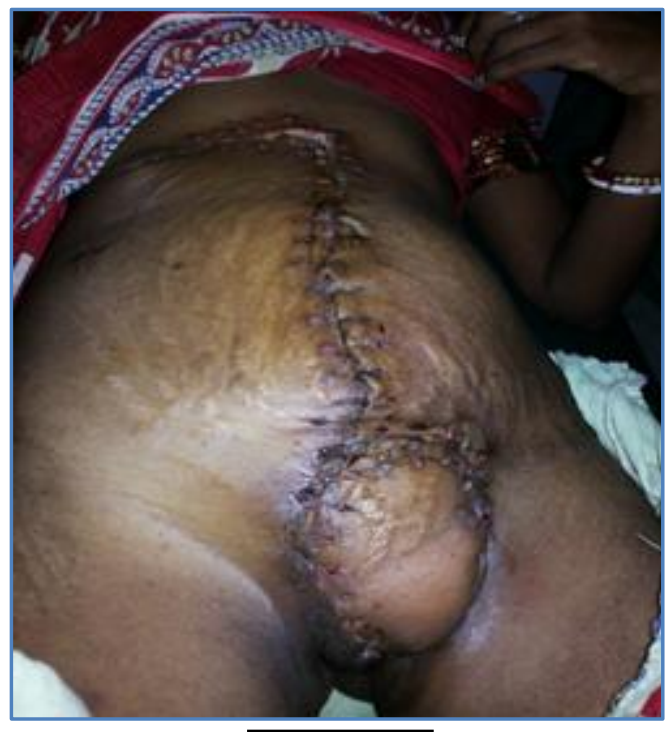

Fig. 2 b

DISCUSSION: Soft tissue sarcoma may occur in any part of body, though it is rare in pubic region. ${ }^{[4]}$

As we all know that treatment of choice for soft tissue sarcoma is radical surgical resection but it may cause large defect. Local or distant flaps, or free-tissue transfer are the options for reconstructive procedure following ablative surgery of such cases.

The advantages of pedicled Standard VRAM are providing ample skin, soft tissue bulk, simplicity of execution, low complication rate, and high success rate.[5] In addition, presence of valves in veins of the inferior epigastric system and intramuscular lymphatic bundles in the rectus muscle reduces the incidence of venous stasis, oedema and lymphoedema in the dependent portion of these large flaps.[6],[7] The local muscle flaps in this region are often hypovascular and fibrotic rendering them insufficient to provide sufficient soft tissue coverage.

CONCLUSION: The VRAM flaps would offer reliable reconstructive options for coverage of large primary wound after radical resection of lower abdominal, groin, perineal, vaginal and proximal lower limb musculoskeletal sarcoma. They offer larger well-vascularized, more durable soft tissue coverage of recipient site with usually acceptable primary closure of donor site without delay in the postoperative adjuvant therapy, good functional outcome.

\section{REFERENCES:}

1. M Kuwahara, M Hatoko, T Okazaki, A Shiba, A Tanaka, T Muramatsu, T Shirai. Coverage of a defect after groin dissection using a pedicled rectus abdominis musculocutaneous flap. Annals of.Plastic.Surgery.1998; 41 (2): 222-3.

2. GI Taylor, R Corlett, JB Boyd. The extended deep inferior epigastric flap: a clinical technique. Plastic and ReconstructiveSurgery.1983; 72 (6): 751-64. 


\section{CASE REPORT}

3. ME Gottlieb, B Chandrasekhar, JJ Terz, R Sherman. Clinical applications of the extended deep inferior epigastric flap. Plastic \& amp Reconstructive Surgery.1987; 78 (6): 782-92.

4. MM Kearney, EH Soule, JC Ivins. Malignant fibrous histiocytoma.Cancer.1980; 45: 167-78

5. BS Glatt, JJ Disa, BJ Mehrara, AL Pusic, P Boland, PG Cordeiro. Reconstruction of extensive partial or total sacrectomy defects with a trans abdominal vertical rectus abdominismyocutaneous flap. Annals of Plastic Surgery. 2006; 56 (5): 526-31.

6. CC Cedidi, G Felmerer, a Berger. Management of defects in the groin, thigh, and pelvic region with modified contralateral TRAM/VRAM flaps. European Journal of MedicalResearch.2005; 10 (12): 515-20.

7. A Senchenkov, NR Thomford, FEB arone. Reconstruction of an extensive thigh defect with the paraumbilical TRAM flap. Annals of Plastic Surgery.2003; 519 (1): 91-96.

\section{AUTHORS:}

1. Santanu Sarkar

2. Sukhamoy Saha

3. Manabendra Naskar

4. Madhusudan Saha

5. Prasenjeet Mondal

\section{PARTICULARS OF CONTRIBUTORS:}

1. Clinical Tutor, Department of General Surgery, Burdwan Medical College \& Hospital, Burdwan, West Bengal, India.

2. Assistant Professor, Department of General Surgery, Burdwan Medical College \& Hospital, Burdwan, West Bengal, India.

3. Post Graduate Trainee, Department of General Surgery, Burdwan Medical College \& Hospital, Burdwan, West Bengal, India.

4. Senior Resident, Department of General Surgery(SR), Burdwan Medical College \& Hospital, Burdwan, West Bengal, India.
5. Post Graduate Trainee, Department of General Surgery, Burdwan Medical College \& Hospital, Burdwan, West Bengal, India.

\section{NAME ADDRESS EMAIL ID OF THE CORRESPONDING AUTHOR:}

Santanu Sarkar,

1/3/1C,

Ramlal Agarwala Lane,

Sinthee,

Kolkata-700050.

Email: drsantanu.surg@gmail.com

Date of Submission: 18/07/2014.

Date of Peer Review: 19/07/2014.

Date of Acceptance: 30/07/2014.

Date of Publishing: 05/08/2014. 